$\left.\begin{array}{c}\text { Kalpa Publications in Engineering } \\ \text { Volume 3, 2020, Pages 26-35 } \\ \text { Proceedings of International Sym- } \\ \text { posium on Applied Science 2019 }\end{array}\right)$ Kalpel

\title{
Color Reduction Of Biodiesel From Crude Palm Oil By Using Activated Carbon Prepared From Chilli Stem
}

\author{
Yuvarat Ngernyen, Werawit Phiewruangnont, Ratchapon Anachai, and \\ Andrew J. Hunt \\ Khon Kaen University, Thailand \\ nyuvarat@kku.ac.th, werawit.1996@gmail.com, \\ Ratchapon2020@gmail.com, andrew@kku.ac.th
}

\begin{abstract}
This present work aims to reduce the color of biodiesel from crude palm oil through the application of activated carbon prepared from chili stem waste. Chilli stem was converted into activated carbon using $30 \mathrm{wt} \% \mathrm{KOH}$ at a ratio of $1: 2$ for $1 \mathrm{~h}$, followed by carbonization at $500{ }^{\circ} \mathrm{C}$ under an $\mathrm{N}_{2}$ atmosphere for a further hour. Physico-chemical characteristics of the raw material and activated carbon were analyzed including thermogravimetric analysis, proximate analysis, and porosities. The results demonstrated that the activated carbon was a porous material with a highly mesoporous structure $(84.5 \%)$. The surface area of activated carbon was $10.6 \mathrm{~m}^{2} / \mathrm{g}$ and it exhibited an average pore diameter of $27.25 \mathrm{~nm}$ which was suitable for the removal of large highly colored molecules. Batch adsorption experiments were performed to investigate the reduction in color of the biodiesel. Ratios of activated carbon to biodiesel of 0.002 and $0.1 \mathrm{w} / \mathrm{v}$ were used in the study. For comparison, the adsorption was also tested against a commercial activated carbon with a surface area of $1,130 \mathrm{~m}^{2} / \mathrm{g}$, but lower average pore size of 3.72 $\mathrm{nm}$. The chili stem activated carbon can reduce color by approximately $15 \%$ within $24 \mathrm{~h}$ and the maximum color reduction was $95 \%$ after $96 \mathrm{~h}$ for both activated carbon to biodiesel ratios. The color of biodiesel changes from dark red to yellow and eventually resulted in a pale yellow color with longer adsorption times and was deemed more attractive for use. Moreover, commercial activated carbon with its small pore size could not reduce the color, with a maximum reduction of only $3 \%$.
\end{abstract}

\section{Introduction}

One public company in Vientiane, Lao People's Democratic Republic, has many products such as oil palm varieties, crude palm oil, palm olein, biodiesel oil, and organic fertilizer. However, the color of biodiesel from crude palm oil is red dark (Fig. 1) and therefore limits its use. So, this research intends 
to reduce this color.

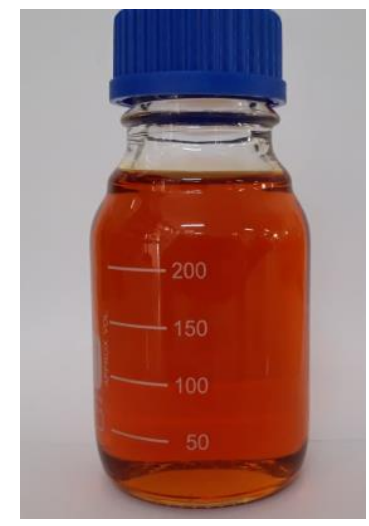

Figure 1: Biodiesel from crude palm oil.

The adsorption process is one of the most suitable methods for color removal of liquid phase due to its high efficiency, simplicity of design and economic considerations. Commonly used adsorbents are comprised of activated carbon, zeolite, biomasses, polymer and polymer composites [1]. However, activated carbon is one of the most effective adsorbents due to its high adsorption capacity. Recently, numerous approaches have been studied for the development of cheaper and effective activated carbon. Many low-cost materials including natural and waste materials from agriculture, municipal and industry such as barley straw [2], kenaf core fiber [3], wood [4, 5], Jatropha curcas [6], corncob [7], coal [8], black liquor lignin [9], sewage sludge [10], waste tires [11], etc have been proposed by several workers. Chilli is the fruit of the plant from the genus Capsicum [12]. Chilli is herbaceous and widely used in many cuisines as a spice to add heat to dishes. People can eat whole chili fruit except the stem, therefore the stem is considered food waste. Moreover, no research has focused on the use of chili stem as raw material for the production of activated carbon.

Generally, activated carbon is prepared by either a physical or chemical activation process. The physical activation involves two steps, carbonization and activation, which require a high temperature of $500-1000^{\circ} \mathrm{C}$ [13]. Chemical activation usually involves only one step wherein carbonization and activation is completed after the raw material has been impregnated with activating agents such as $\mathrm{H}_{3} \mathrm{PO}_{4}, \mathrm{H}_{2} \mathrm{SO}_{4}, \mathrm{KOH}, \mathrm{ZnCl}_{2}, \mathrm{FeCl}_{3}$, etc. Chemical activation has an advantage over physical activation due to requiring temperature is lower $\left(400-700^{\circ} \mathrm{C}\right)$ [14], yielding a higher surface area carbon.

This study focuses on the development of activated carbon derived from chili stem by $\mathrm{KOH}$ activation. The produced activated carbon is then used as adsorbents for remove the color of biodiesel and compared to the performance of commercial activated.

\section{Materials and Methods}

\subsection{Materials}

Chilli stem (Figure 2 (a)) collected from the food market in Khon Kaen, Thailand was washed several times and sun-dried. Then it was cut into small pieces and sieved to an average particle size 4 $\mathrm{mm}$ (mesh no. 5) as shown in Figure 2 (b). 


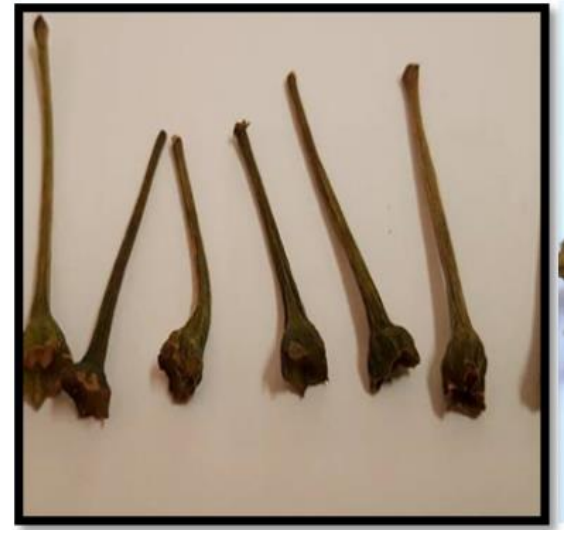

(a)

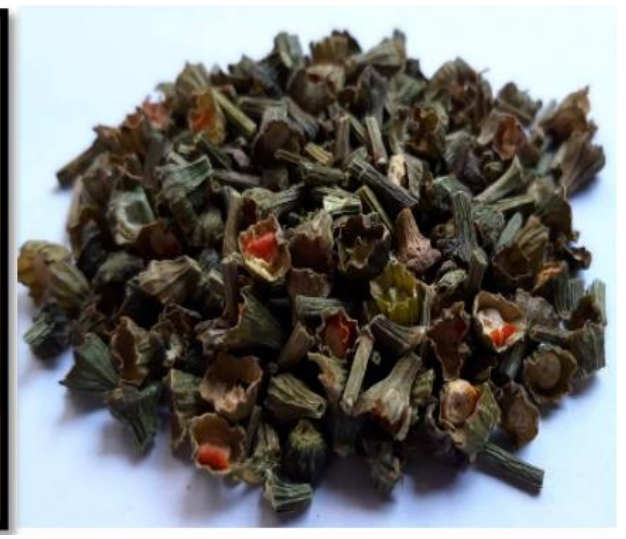

(b)

Figure 2: Chilli stem (a) before and (b) after size-reduction

\subsection{Preparation of activated carbon}

In this study, the chemical activation of the chili stem was carried out by using a $30 \mathrm{wt} \% \mathrm{KOH}$ solution as the activating agent. The impregnation ratio of $\mathrm{KOH}$ to the weight of the chili stem was 2:1. The mixture was kept at room temperature for $1 \mathrm{~h}$. The carbonization of the impregnated sample was carried out in a fixed-bed reactor and heated to $500{ }^{\circ} \mathrm{C}$ and held for $1 \mathrm{~h}$ under a nitrogen atmosphere. The carbonized product was washed several times with hot distilled water until the $\mathrm{pH}$ of the washing solution was neutral. The resulting activated carbon was dried in an oven at $120{ }^{\circ} \mathrm{C}$ for $6 \mathrm{~h}$ and then stored in plastic containers.

Commercial powdered activated carbon obtained from a company in Nakhon Ratchasima, Thailand was used for comparison with chili stem carbon.

\subsection{Characterization}

The textual properties of the chili stem and commercial activated carbons were characterized by determining the nitrogen gas adsorption and desorption isotherms at $-196^{\circ} \mathrm{C}$ or $77 \mathrm{~K}$ using an automatic adsorption instrument (ASAP 2460, Micromeritics). Before adsorption measurement, the samples were degassed at $300^{\circ} \mathrm{C}$ under vacuum for $5 \mathrm{~h}$. The adsorption isotherm was obtained over a relative pressure $\left(\mathrm{P} / \mathrm{P}^{\circ}\right)$ ranging from $10^{-3}$ to 0.99 . The surface area $\left(\mathrm{S}_{\mathrm{BET}}\right)$ and micropore volume $\left(\mathrm{V}_{\text {mic }}\right)$ of the activated carbons were determined by the application of the Brunauer-Emmett-Teller (BET) and Dubinin Radushkevick (DR) equation, respectively. The total pore volume, $\mathrm{V}_{\mathrm{T}}$, was estimated at $\mathrm{P} / \mathrm{P}^{\mathrm{o}} \sim 0.99$. The mesopore volume $\left(\mathrm{V}_{\text {mes }}\right)$ was determined by subtracting the $\mathrm{V}_{\text {mic }}$ from the $\mathrm{V}_{\mathrm{T}}$ while the $\% \mathrm{~V}_{\text {mic }}$ and $\% \mathrm{~V}_{\text {mes }}$ were based on $\mathrm{V}_{\mathrm{T}}$. The average pore diameter or $\mathrm{D}_{\mathrm{P}}$ of the activated carbon was obtained by applying the Barrett-Joyner-Halenda (BJH) method.

The proximate analysis includes moisture, volatile matter, fixed carbon and ash contents of raw material and activated carbon was also determined. The thermal drying method follows ASTM D2867 was used in the determination of moisture content of the samples. About $1 \mathrm{~g}$ of the sample was weighted in triplicate and placed in the crucible. The crucibles were placed in an oven at $150{ }^{\circ} \mathrm{C}$ to constant weight for $3 \mathrm{~h}$. The difference between the initial and final mass of the sample represents the moisture content. For volatile matter, about $1 \mathrm{~g}$ of the sample was heated at a temperature of $950{ }^{\circ} \mathrm{C}$ for $30 \mathrm{~min}$ by using furnace according to the method of ASTM D5832-98. The volatile weight is the difference in weight 
before and after heating of the sample. For ash content, the crucible that contains $1 \mathrm{~g}$ of sample was placed in the furnace and the temperature was allowed to rise to $800{ }^{\circ} \mathrm{C}$ for $2 \mathrm{~h}$. The remaining sample after heating was ash. Finally, fixed carbon content found from the subtraction of $100 \%$ with \% moisture, $\%$ ash, and \%volatile.

The thermal behavior of the chili stem was measured with a thermogravimetric analyzer (TGA-50, Shimadzu). About $10 \mathrm{mg}$ of sample was heated from room temperature to $700{ }^{\circ} \mathrm{C}$ at a rate of $10{ }^{\circ} \mathrm{C} \mathrm{min}-$

${ }^{1}$ under the nitrogen gas atmosphere with a low rate of $200 \mathrm{~cm}^{3} \mathrm{~min}^{-1}$. Then, percent weight loss versus temperature plots was taken for the thermogravimetric analysis.

\subsection{Color removal of biodiesel}

To evaluate the potential of prepared activated carbon for color removal of biodiesel, batch adsorption experiments were used. A $50 \mathrm{~mL}$ of biodiesel was placed in a flask and subsequently, $0.1 \mathrm{~g}$ and $0.5 \mathrm{~g}$ of activated carbon were added. This results in the ratio of activated carbon to biodiesel 0.002 and $0.01 \mathrm{w} / \mathrm{v}$, respectively. The flasks were shaken by shaker at $120 \mathrm{rpm}$ at room temperature for desired adsorption time ranging from 12 to $96 \mathrm{~h}$. After shaking, a centrifuge ( $3500 \mathrm{rpm}, 30 \mathrm{~min}$ ) was used to separate the activated carbon from biodiesel. The color of biodiesel was determined by measure its absorbance using a UV-visible spectrophotometer (Analytik-Jena AG). The \% color reduction was calculated from the difference between the absorbance of biodiesel before and after adsorption.

\section{Results and Discussion}

\subsection{Thermogravimetric analysis of raw material}

Thermogram obtained from the TG analysis of the chili stem as a function of temperature is shown in Figure 3. The first step which occurs at temperatures ranging from room temperature to $150{ }^{\circ} \mathrm{C}$ involves the loss of moisture present in the sample with approximately the weight loss of about $12 \%$. The second weight-loss step with approximately the weight loss of about $37 \%$ have occurred at 150 $300{ }^{\circ} \mathrm{C}$. This step is related to the decomposition of hemicellulose [15]. In the third step, the occurring at $300-410^{\circ} \mathrm{C}$ with the weight loss of $36 \%$ is the decomposition of cellulose and lignin [15]. Finally, in the fourth step (temperature above $410{ }^{\circ} \mathrm{C}$ ), the slightly continue weight loss of about $5.4 \%$ is observed. This temperature can be said to be the lowest carbonization temperature for the preparation of activated carbon from the chili stem. Therefore, in this study $500{ }^{\circ} \mathrm{C}$ was chosen to carbonize the raw material. 


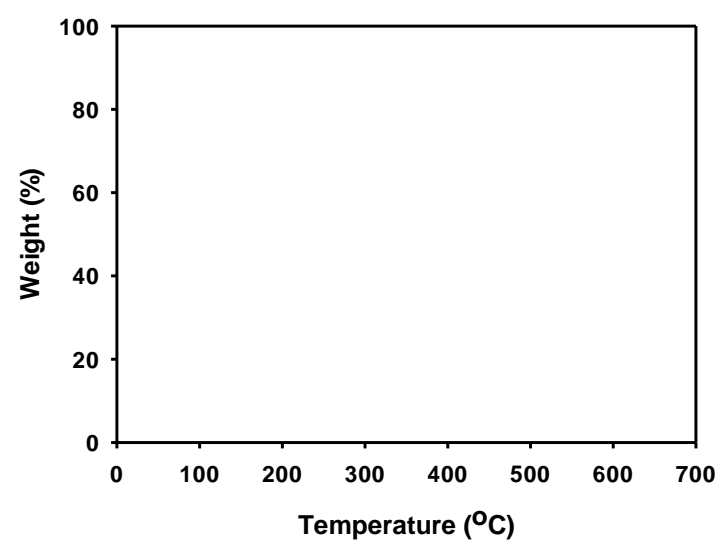

Figure 3: TGA curve of chili stem.

\subsection{Proximate analysis}

The results of the proximate analysis of raw material and activated carbon were shown in Table 1. The chili stem contains $13.2 \%$ moisture which similar to TGA results. It is also shown that chili stem has a reasonable amount of fixed carbon (17.3\%) which indicated that this waste can be a potential precursor material for the preparation of activated carbon.

It can be seen that the fixed carbon content increased in the activated carbon sample whereas volatile matter content decreased. This is due to the release of volatiles during carbonization that results in the elimination of the non-carbon species. The chili stem activated carbon had a low moisture content of about $2.3 \%$ indicate the hydrophobicity of the material. The activated carbon also possessed low ash content $(2.5 \%)$ indicating a high-quality carbon adsorbent. Ash content influences the ignition point of the activated carbon and it reduced the overall activity of activated carbon and the efficiency of reactivation [16].

\begin{tabular}{lcc}
\hline & Chilli Stem & Activated Carbon \\
\hline Moisture & 13.2 & 2.3 \\
\hline Volatile Matter & 59.3 & 31.7 \\
\hline Ash & 10.2 & 2.5 \\
\hline Fixed carbon & 17.3 & 63.5
\end{tabular}

Table 1: Proximate analysis (wt\%) of chili stem and activated carbon

\subsection{Porosities analysis}

Adsorption-desorption isotherms of $\mathrm{N}_{2}$ at $-196{ }^{\circ} \mathrm{C}$ of the activated carbon prepared from chili stem and commercial activated carbon are shown in Figure 4. For chili stem activated carbon, the initial part of adsorption isotherm is Type I according to IUPAC classification with a desorption hysteresis loop due to adsorbate condensation in the mesopore is presented. The hysteresis loop is usually associated with monolayer-multilayer adsorption followed by capillary condensation in mesoporous structure [17]. The prepared activated carbon had a mixture of micro and mesoporosity. 


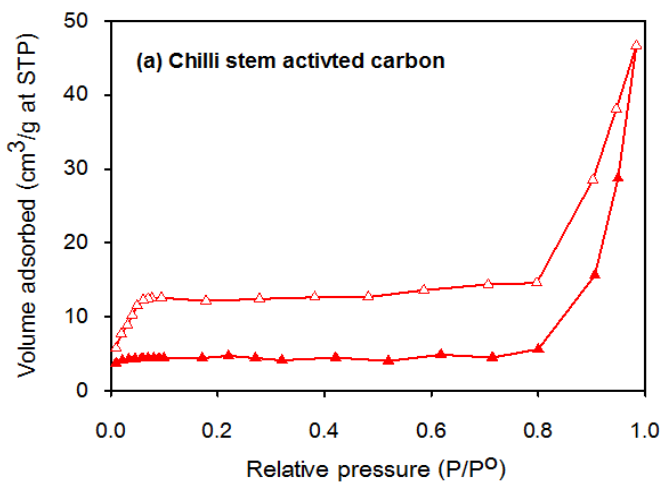

(a)

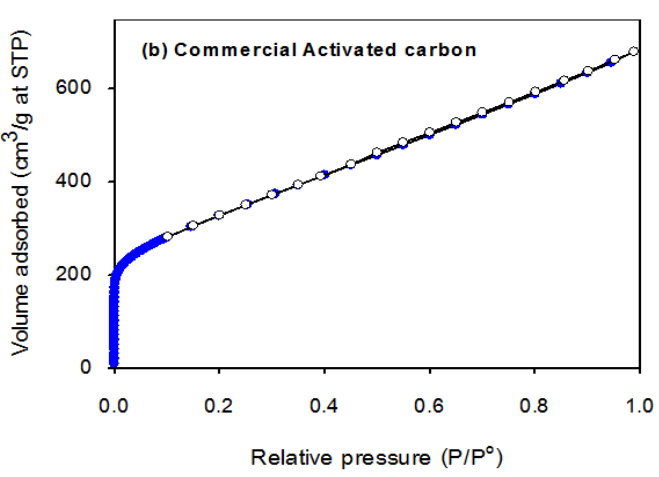

(b)

Figure 4: $\mathrm{N}_{2}$ adsorption (filled symbols) and desorption (empty symbols) isotherms of (a) chili stem activated carbon and (b) commercial activated carbon.

The isotherm of commercial activated carbon is Type IV indicates a mainly mesoporous material. The volume of $\mathrm{N}_{2}$ adsorbed increase steepness over the relative pressure range observed. It can be observed that the $\mathrm{N}_{2}$ adsorption isotherm of activated carbon prepared from chili stem exhibited a much lower adsorption capacity than commercial activated carbon. The low $\mathrm{N}_{2}$ adsorbed amount was indicative of less of the porous structure.

Based on $\mathrm{N}_{2}$ adsorption isotherms, BET surface area and porous texture of chili stem activated carbon and commercial activated carbon are given in Table 2. Specific surface area and total pore volume of $10.6 \mathrm{~m}^{2} / \mathrm{g}$ and $0.072 \mathrm{~cm}^{3} / \mathrm{g}$ were obtained for activated carbon prepared from the chili stem. These values are quite low but the pore size is large to $27.25 \mathrm{~nm}$. The adsorbents pores are classified as micropore (diameter $<2 \mathrm{~nm}$ ), mesopore $(2<$ diameter $<50 \mathrm{~nm}$ ) and macropore (diameter $>50 \mathrm{~nm}$ ). Thus, it is predicted that this pore size is suitable for adsorbed large color molecules of biodiesel.

In the case of commercial activated carbon, it has a large surface area and total pore volume of 1,130 $\mathrm{m}^{2} / \mathrm{g}$ and $1.050 \mathrm{~cm}^{3} / \mathrm{g}$, respectively. The results also indicate the presence of a significant amount of mesopores (96\%) and a small number of micropores (4\%), with an average pore size of $3.72 \mathrm{~nm}$.

\begin{tabular}{lccccc}
\hline Sample & $\begin{array}{c}S_{\mathrm{BET}} \\
\left(\mathrm{m}^{2} / \mathrm{g}\right)\end{array}$ & $\begin{array}{c}V \mathrm{mic} \\
\left(\mathrm{cm}^{3} / \mathrm{g}\right)\end{array}$ & $\begin{array}{c}V \text { meso } \\
\left(\mathrm{cm}^{3} / \mathrm{g}\right)\end{array}$ & $\begin{array}{c}V_{\mathrm{T}} \\
\left(\mathrm{cm}^{3} / \mathrm{g}\right)\end{array}$ & $\begin{array}{c}D_{\mathrm{P}} \\
(\mathrm{nm})\end{array}$ \\
\hline $\mathrm{AC}$ & 10.6 & $\begin{array}{c}0.008 \\
(11 \%)\end{array}$ & $\begin{array}{c}0.064 \\
(89 \%)\end{array}$ & 0.072 & 27.25 \\
$\mathrm{C}-\mathrm{AC}$ & 1,130 & $\begin{array}{c}0.046 \\
(4 \%)\end{array}$ & $\begin{array}{c}1.004 \\
(96 \%)\end{array}$ & 1.050 & 3.72 \\
& & & \\
\hline
\end{tabular}

Table 2: the porous texture of the chili stem activated carbon (AC) and commercial activated carbon (C-AC)

\subsection{Color reduction of biodiesel}

This research hypothesized that the color molecule of biodiesel quite large in size. So, suitable adsorbent should have a large pore size. It can be seen that chili stem activated carbon had a large pore size of $27.25 \mathrm{~nm}$ although it had low surface area and pore volume. To test this hypothesis, commercial activated carbon with high surface area and pore volume but small pore size were used.

Figure 5 shows the color of biodiesel before and after adsorption with chili stem activated carbon at various times for both ratios. The results show that adsorption by chili stem activated carbon can reduce the color of biodiesel from red dark to yellow tone that more attractive for use. At the same ratio, the 
longer adsorption time can reduce the color to pale yellow. Similarly, at the same adsorption time, more amount of activated carbon can reduce more color.

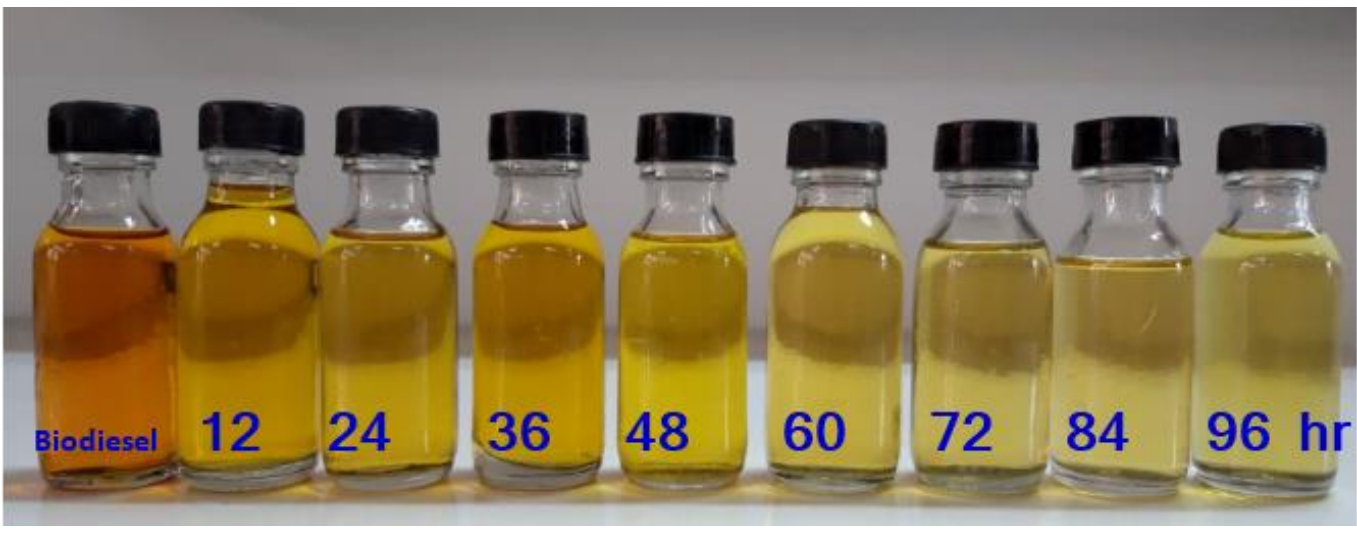

(a) activated carbon : biodiesel $0.002 \mathrm{w} / \mathrm{v}$

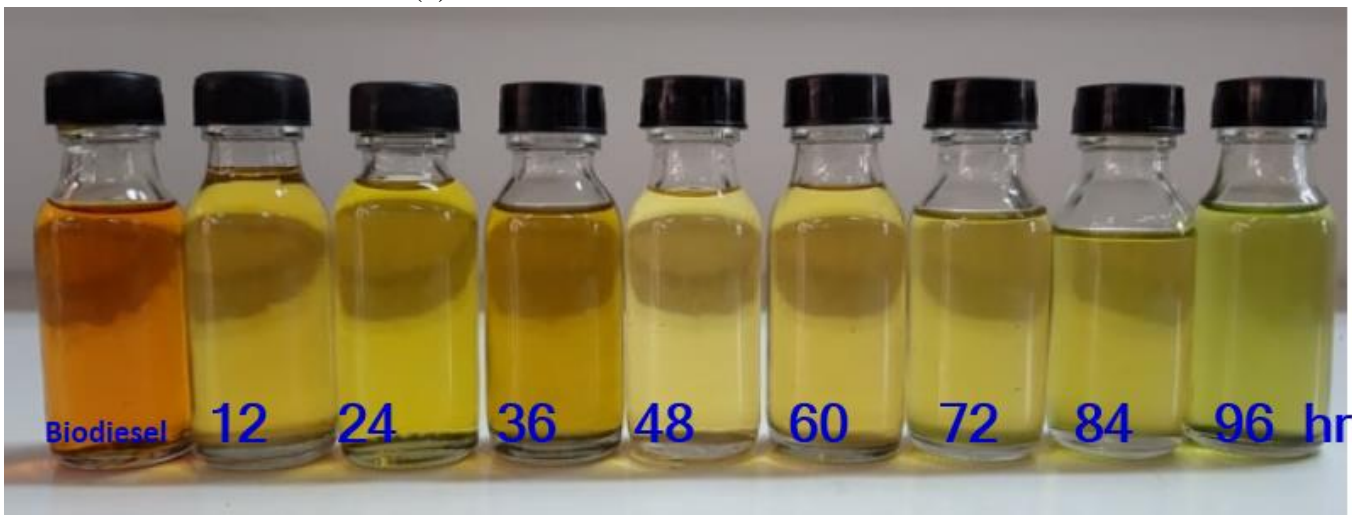

(b) activated carbon : biodiesel $0.1 \mathrm{w} / \mathrm{v}$

Figure 5: Biodiesel color before and after adsorption with chili stem activated carbon at various times.

Figure 6 shows the relationships between the \% color removal of biodiesel and adsorption time of the prepared activated carbon for both activated carbon to biodiesel ratio. It can be seen from the figure that as the adsorption time increases, the \% color removal increases with a significant enhancement within $84 \mathrm{~h}$. The $\%$ removal increased from $15 \%$ at adsorption time $24 \mathrm{~h}$ to a maximum of $95 \% 96 \mathrm{~h}$ for both ratios. The higher amount of activated carbon can remove more color at a $24 \mathrm{~h}$ adsorption time and the adsorption reaches equilibrium at $84 \mathrm{~h}$. The color of biodiesel from the UV-visible spectrophotometer (under $\mathrm{x}$-axis) also demonstrated comparable results in Figure 5. 


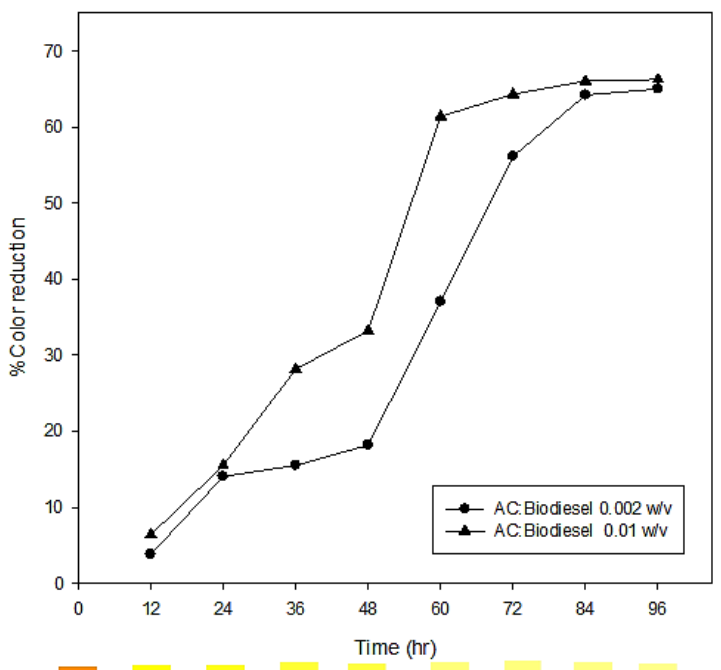

AC:Biodiesel $0.002 \mathrm{WN}$

AC.Biodiesel $0.01 \mathrm{w} / \mathrm{v}$

Figure 6: \% Color removal of biodiesel after adsorption at various times with chili stem activated carbon.

Figure 7 depicted the \% color removal of chili stem activated carbon compare with commercial activated carbon. It was evident that commercial activated carbon with a high surface area but a small pore size that cannot remove the color of biodiesel only $3 \%$. This confirmed our hypothesis that activated carbon with a large pore size is suitable to remove the color of biodiesel than activated carbon with small pore size.

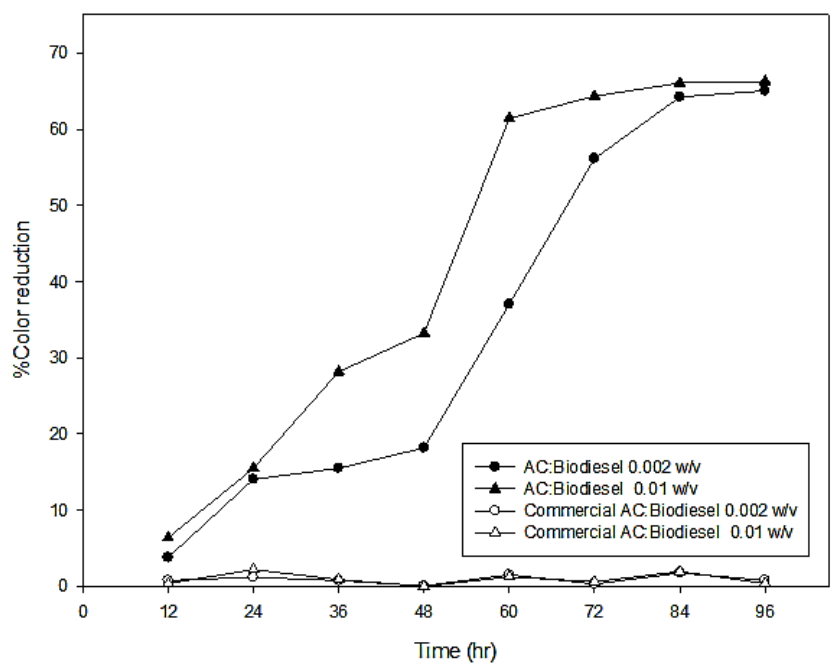

Figure 7: \% Color removal of biodiesel with chili stem activated carbon compare with commercial activated carbon. 


\section{Conclusion}

The results of this study demonstrated that low-cost activated carbon can be prepared from chili stem by chemical activation with $\mathrm{KOH}$ for color reduction of biodiesel. Activated carbon with the BET surface area of $10.6 \mathrm{~m}^{2} / \mathrm{g}$ and an average pore size of $27.25 \mathrm{~nm}$ was obtained. The prepared chili stem activated carbon is identified as being appropriate adsorbent for removal of the color of biodiesel due to its large pore size. The results show that the color reduction of prepared activated carbon was superior to commercial activated carbon that had a high surface area of $1,130 \mathrm{~m}^{2} / \mathrm{g}$ and average pore size of 3.72 $\mathrm{nm}$. The color of biodiesel changes from red dark tone to yellow tone that more attractive to use. This demonstrated that chili stem activated carbon had the potential for removal of biodiesel color and it can be an alternative to the low-cost adsorbent.

\section{Acknowledgment}

This research was supported by the Faculty of Engineering, Khon Kaen University.

\section{References}

[1] A. A. Alghamdi, A.-B. Al-Odayni, W. S. Saeed, A. Al-Kahtani, F. A. Alharthi, and T. Aouak, "Efficient adsorption of lead (II) from aqueous phase solutions using polypyrrole-based activated carbon," Materials, vol. 12, pp. 1-16, 2020.

[2] J. Pallarés, A. González-Cencerrado, and I. Arauzo, "Production and characterization of activated carbon from barley straw by physical activation with carbon dioxide and steam," Biomass Bioenerg., vol. 115, 64-73, 2018.

[3] M. S. Shamsuddin, N. R. N. Yusoff, and M. A. Sulaiman, "Synthesis and characterization of activated carbon produced from kenaf core fiber using $\mathrm{H}_{3} \mathrm{PO}_{4}$ activation," Procedia Chem., vol. 19, 558-565, 2016.

[4] A. Heidari and $\mathrm{H}$. Younesi "Adsorptive removal of $\mathrm{CO}_{2}$ on highly microporous activated carbons prepared from Eucalyptus camaldulensis wood: Effect of chemical activation," J. Taiwan Inst. Chem. Eng., vol. 45, pp. 579-588, 2014.

[5] S. Yorgun and D. Yildiz, "Preparation and characterization of activated carbons from Paulownia wood by chemical activation with $\mathrm{H}_{3} \mathrm{PO}_{4}$," J. Taiwan Inst. Chem. Eng., vol. 53, pp. 122-131, 2015.

[6] W. Tongpoothorn, M. Sriuttha, P. Homchan, S. Chanthai and C. Ruangviriyachai, "Preparation of activated carbon derived from Jatropha curcas fruit shell by simple thermos-chemical activation and characterization of their physico-chemical properties," Chemical Engineering Research and Design, vol. 89, pp. 335-340, 2011.

[7] G. O. El-Sayed, M. M. Yehia, and A. A. Asaad. "Assessment of activated carbon prepared from corncob by chemical activation with phosphoric acid," Water Resources and Industry, vol. 7-8, pp. 66-75, 2014.

[8] E. N. E. Qada, S. J. Allen, and G. M. Walker, "Adsorption of methylene blue onto activated carbon produced from steam activated bituminous coal: A study of equilibrium adsorption isotherm," Chemical Engineering Journal, vol. 124, pp. 103-110, 2006.

[9] K. Fu, Q. Yue, B. Gao, Y. Sun, and L. Zhu, "Preparation, characterization and application of ligninbased activated carbon from black liquor lignin by steam activation," Chemical Engineering Journal, vol. 228, pp. 1074-1082, 2013.

[10] M. H. Al-Malack and M. Dauda, "Competitive adsorption of cadmium and phenol on activated carbon produced from municipal sludge," Journal of Environmental Chemical Engineering, vol. 5, pp. 2718-2729, 2017. 
[11] A. S. Al-Rahbi and P. T. Williams, "Production of activated carbons from waste tyres for lowtemperature NOx control," Waste Management, vol. 49, pp. 188-195, 2016.

[12]L. Colney, W. Tyagi, and M. Rai, "Morphological and molecular characterization of two distinct chilli cultivars drom North Eastern India with special reference to pungency related gened," Scientia Horticulturae, vol. 240, pp. 1-10, 2018.

[13] A. E. Ogungbenro, D. V. Quang, K. A. Al-Ali, L. F. Vega, and M. R. M. Abu-Zahra, "Physical synthesis and characterization of activated carbon from date seeds for $\mathrm{CO}_{2}$ capture," J. Environ. Chem. Eng., vol. 6, pp. 4245-4252, 2018.

[14] M. S. Shamsuddin, N. R. N. Yusoff, and M. A. Sulaiman, "Synthesis and characterization of activated carbon produced from kenaf core fiber using $\mathrm{H}_{3} \mathrm{PO}_{4}$ activation," Procedia Chem., vol. 19, 558-565, 2016.

[15]H. Sayg1lı and F. Güzel, "High surface area mesoporous activated carbon from tomato processing solid waste by zinc chloride activation: process optimization, characterization and dyes adsorption," Journal of Cleaner Production, vol. 113, 995-1004, 2016.

[16] O. A. Ekpete, A. C. Marcus, and V. Osi, "Preparation and characterization of activated carbon obtained from plantain (Musa paradisiaca) fruit stem," Journal of Chemistry, Article ID 8635615, 2017.

[17]T. Mi, L. Chen, S.-z. Zin, and X.-m. Yu, "Activated carbon from the Chinese herbal medicine waste by $\mathrm{H}_{3} \mathrm{PO}_{4}$ activation," Journal of Nanomaterials, Article ID 910467, 2015. 